Article

\title{
Evolutionary Insights of the ZW Sex Chromosomes in Snakes: A New Chapter Added by the Amazonian Puffing Snakes of the Genus Spilotes
}

\author{
Patrik F. Viana ${ }^{1,2, *}{ }^{1}$, Tariq Ezaz ${ }^{2}\left(\mathbb{D}\right.$, Marcelo de Bello Cioffi ${ }^{3}$, Breno Jackson Almeida ${ }^{4}$ and \\ Eliana Feldberg ${ }^{1}$ \\ 1 Instituto Nacional de Pesquisas da Amazônia, Coordenação de Biodiversidade, Laboratory of Animal \\ Genetics, Av. André Araújo 2936, Petrópolis, Manaus CEP 69067-375, AM, Brazil; feldberg@inpa.gov.br \\ 2 Institute for Applied Ecology, Faculty of Science and Technology, University of Canberra, Canberra, \\ ACT 2616, Australia; Tariq.Ezaz@canberra.edu.au \\ 3 Departamento de Genética e Evolução, Universidade Federal de São Carlos, São Carlos 13565-905, SP, Brazil; \\ mbcioffi@ufscar.br \\ 4 Centro Amazônico de Herpetologia-Amazonian Center for Herpetology, Benevides 68795-000, PA, Brazil; \\ brenojlalmeida@hotmail.com \\ * Correspondence: patrik.biologia@gmail.com; Tel.: +61-04-04591716
}

Received: 4 January 2019; Accepted: 31 March 2019; Published: 9 April 2019

\begin{abstract}
Amazonian puffing snakes (Spilotes; Colubridae) are snakes widely distributed in the Neotropical region. However, chromosomal data are scarce in this group and, when available, are only limited to karyotype description using conventional staining. In this paper, we focused on the process of karyotype evolution and trends for sex chromosomes in two Amazonian Puffer Snakes (S. pulllatus and S. sulphureus). We performed an extensive karyotype characterization using conventional and molecular cytogenetic approaches. The karyotype of $S$. sulphureus (presented here for the first time) exhibits a $2 n=36$, similar to that previously described in $S$. pullatus. Both species have highly differentiated ZZ/ZW sex chromosomes, where the $\mathrm{W}$ chromosome is highly heterochromatic in S. pullatus but euchromatic in S. sulphureus. Both $\mathrm{W}$ chromosomes are homologous between these species as revealed by cross-species comparative genomic hybridization, even with heterogeneous distributions of several repetitive sequences across their genomes, including on the $\mathrm{Z}$ and on the $\mathrm{W}$ chromosomes. Our study provides evidence that $\mathrm{W}$ chromosomes in these two species have shared ancestry.
\end{abstract}

Keywords: advanced snakes; sex chromosomes; heterochromatin; $\mathrm{CGH}$; repeat accumulation; Amazonian snakes

\section{Introduction}

The Colubridae family represents one of the most widely distributed groups of Caenophidian snakes, with more than 1800 species currently recognized [1]. It is considered to be a monophyletic group supported by both morphological and molecular analyzes [2-6]. Many species are found in the Neotropical region, which is well known for its high biodiversity and complex evolutionary history [7-10]. The Amazon puffing snakes (Spilotes spp.) are among the largest species of the New World Colubrids [11-13], occurring in different morpho-climatic landscapes in South America [14-16]. Previously, Spilotes sulphureus was described within the Pseustes genus [17]. However, Jadin et al. [18] relocated 'Pseustes sulphureus' to Spilotes genus. The renamed Spilotes sulphureus became the sister taxon of S. pullatus and together formed a monophyletic group that is a sister taxon to the genus Phrynonax, all of which together constitute a monophyletic group. 
The vast majority of snakes have diploid numbers (2n) of 36 chromosomes, containing 16 macrochromosomes and 20 microchromosomes [19,20]. However, variations involving macro and micro karyotypic structure and a diploid number have also been reported in different families across snake lineages [21-25]. Although different modes and systems of sex determination have been described (e.g.,) in reptiles [26-30], only genetic sex determination (GSD) with female heterogamety (ZZ/ZW system) occurs in snakes [26,31], although an XY system has been proposed for Boa imperator and Python bivittatus [32]. Nevertheless, the sex chromosomes of many species of snakes remained undifferentiated, with no huge morphological shifts (e.g., Boidae and Phytonidae), with a low degree of differentiation between $\mathrm{Z}$ and $\mathrm{W}$ sex chromosomes [33-36], making them undetectable using conventional cytogenetics techniques. Even in Caenophidian snakes, such as in some Colubridae [37], where several repetitive sequences are known to be the main source of differentiation of $\mathrm{W}$ sex chromosomes [38], they can remain undetectable. Likewise, the $\mathrm{Z}$ chromosome seems to share the same gene content across ancestral and advanced snakes [33,35,39], without large morphological modifications [40].

It is a common feature for some reptile lineages to present a limited level of degeneration of the sex chromosomes, which makes them undetectable under conventional cytogenetic procedures. However, fine-scale molecular cytogenetic techniques (e.g., Comparative Genomic Hybridization; Chromosomal Painting; Bacterial Artificial Chromosome - BAC) have been providing a better understanding regarding the processes of evolution of the sex chromosomes in vertebrates (reviewed in [41]), as well as in comparative approaches among related species [42,43].

So far, most of the refined studies regarding the evolutionary trends of sex chromosomes in snakes were performed only on some Caenophidians' lineages $[34,37,38,44]$, which represent a gap in the knowledge of the evolutionary pathways of the $\mathrm{W}$ across snake lineages. For instance, in the most recently evolved clades of Caenophidians (Spilotes and Phrynonax), only conventional cytogenetic data exist [22]. For Spilotes, the cytogenetic data available are limited to a karyotype description for the two species of the Spilotes genus (S. pullatus: $2 \mathrm{n}=36$ and S.sulphureus: $2 \mathrm{n}=38$ ) using conventional staining [22]. In this paper, we focused on the process of karyotype evolution and trends of sex chromosome differentiation in the clade that harbors the most recently evolved species among Caenophidian snakes. In order to achieve this, our aim was to perform an extensive karyotype characterization using conventional and molecular cytogenetic approaches in two Amazonian Puffer Snakes (S. pulllatus and S. sulphureus), to characterize sex chromosome differentiation, as well as to describe cytotaxonomy in the Spilotes clade.

\section{Materials and Methods}

\subsection{Sampling, Mitotic Chromosomes Preparation, C-Banding, and Ag-NORs}

The snakes were collected under permission granted by Instituto Chico Mendes de Conservação da Biodiversidade (ICMBio) number: 45275-18 along the Amazon Region. We analyzed 1 male and 1 female of Spilotes sulphureus (Far Western and Central Amazon) and 2 males and 2 females of Spilotes pullatus (Eastern Amazon). Chromosomal preparations were obtained through in vitro culture of blood [45].

The C-positive heterochromatin and Ag-NORs (nucleolar organizer regions) were detected according to Sumner [46] and Howell and Black [47], respectively.

\subsection{Probes for Chromosome Hybridization}

The 18S rDNA and (TTAGGG) $)_{n}$ probes were isolated according to Gross et al. [48] and Ijdo et al. [49], respectively. Both probes were labeled with digoxigenin-11-dUTP using Dig-Nick kit (Bio-NickTranslation Mix, Roche, Mannheim, Germany) following the manufacturer's recommendations (Roche, Mannheim, Germany). Microsatellites motifs (AC) ${ }_{15},\left(\right.$ AG) ${ }_{15},(\text { ATTC })_{8}$, $(\mathrm{ATCC})_{8}$, and (GATA $)_{8}$ were used directly labeled with Cy-3 during the synthesis [50]. 


\subsection{Fluorescence in Situ Hybridization (FISH) for Repetitive DNA Mapping}

Fluorescence in situ hybridization (FISH) followed the protocol described by Pinkel et al. [51], with minor modifications according to Viana et al. [36]. The chromosome slides were denatured in 70\% formamide $/ 2 \times \operatorname{SSC}$ at $70{ }^{\circ} \mathrm{C}$, and further dehydrated in ethanol series $(70 \%, 85 \%$, and $100 \%)$, for $2 \mathrm{~min}$ each. In regard to the hybridization mixture, $20 \mu \mathrm{L}$ (100 ng of each probe, $50 \%$ deionized formamide and $10 \%$ dextran sulfate) were dropped on the slides, and the hybridization was performed for $24 \mathrm{~h}$ at $37^{\circ} \mathrm{C}$ in a moist chamber containing distilled water. The chromosomes were counterstained with $4^{\prime}$ 6-diamidino-2-phenylindole (DAPI, $1.2 \mu \mathrm{g} / \mathrm{mL}$ ) and mounted in antifade solution (Vector, Burlingame, CA, USA).

\subsection{Preparation of Probes for Comparative Genome Hybridization (CGH)}

The gDNA of males and females of both Spilotes species were extracted from blood using the Wizard ${ }^{\circledR}$ Genomic Purification kit (Promega, Madison, WI, USA), according to the manufacturer's recommendations. Two different experimental designs were used for this study. In the first set of experiments, we focused on intraspecific comparisons, with special emphasis on the molecular composition of the sex chromosomes of S. pullatus. In this case, female-derived gDNA of S. pullatus was labeled with biotin-16-dUTP and male gDNAs with digoxigenin-11-dUTP by means of nick translation as described above. The final hybridization mixture for each slide $(20 \mu \mathrm{L})$ was composed of male- and female-derived gDNAs (500 ng each), $20 \mu \mathrm{g}$ of male-derived $\mathrm{C}_{0} \mathrm{t}-1$ DNA (i.e., fraction of genomic DNA enriched for highly and moderately repetitive sequences), prepared according to [52], and the hybridization buffer containing 50\% formamide, $2 \times$ SSC, $10 \%$ SDS, $10 \%$ dextran sulfate and Denhardt's buffer, $\mathrm{pH}$ 7.0. In the second set of experiments (interspecific genomic comparisons), the gDNA of female specimens of S. sulphureus and S. pullatus were hybridized against metaphase chromosomes of female S. pullatus. For this purpose, female-derived gDNAs of S. sulphureus was labeled with digoxigenin-11-dUTP using DIG-nick-translation Mix (Roche, Mannheim, Germany), while female-derived gDNA of S. pullatus was labeled with biotin-16-dUTP using BIO-nick-translation Mix (Roche). The final probe cocktail for each slide was composed of $500 \mathrm{ng}$ of female-derived gDNA of each species, $20 \mu \mathrm{g}$ of male-derived $\mathrm{C}_{0} \mathrm{t}-1$ DNA of $S$. pullatus, and $20 \mu \mathrm{g}$ of male-derived $\mathrm{C}_{0} \mathrm{t}-1$ DNA of S. sulphureus. The probe was ethanol-precipitated, and the dry pellets were resuspended in hybridization buffer, as described above.

\subsection{Comparative Genomic Hybridization (CGH)}

CGH experiments were performed according to Symonová et al. [53]. The slides were incubated at $37^{\circ} \mathrm{C}$ in a dark humid chamber for $72 \mathrm{~h}$. The hybridization signal was detected with anti-digoxigenin-Rhodamin (Roche) diluted in $0.5 \%$ bovine serum albumin (BSA) in phosphate-buffered saline solution (PBS), and avidin-FITC (Sigma, St Louis, MO, USA) diluted in PBS containing 10\% normal goat serum (NGS). The chromosomes were counterstained with DAPI $(1.2 \mu \mathrm{g} / \mathrm{mL})$ and mounted in an antifade solution (Vector, Burlingame, CA, USA).

\subsection{Microscopic Analyzes}

At least 30 metaphase spreads per individual were analyzed to confirm the 2n, karyotype structure, and FISH results. Images were captured using an Olympus BX51 microscope (Olympus Corporation, Ishikawa, Japan) with CoolSNAP. Chromosomes were classified as macrochromosomes (M) and microchromosomes $(\mathrm{mi})$ or as metacentric $(\mathrm{m})$, submetacentric $(\mathrm{sm})$, subtelocentric (st), and acrocentric (a), according to Levan et al. [54]. 


\section{Results}

\subsection{Karyotype}

Both species presented a $2 \mathrm{n}=36$ chromosomes and $16 \mathrm{M}$ and $20 \mathrm{mi}$. S. sulphureus presented $8 \mathrm{~m}+$ $4 \mathrm{sm}+2 \mathrm{st}+2 \mathrm{a}$ and $20 \mathrm{mi}$, with a fundamental number (NF) equal to 50 for males (Figure 1a,c) and 7 $\mathrm{m}+4 \mathrm{sm}+2 \mathrm{st}+3 \mathrm{a} \mathrm{M}$ and $20 \mathrm{mi}$, and a fundamental number (NF) equal to 49 for females (Figure 1b,d). S. pullatus had $6 \mathrm{~m}+4 \mathrm{sm}+4 \mathrm{st}+2 \mathrm{a}$ and $20 \mathrm{mi}$ for males (Figure 1e,g) and $6 \mathrm{~m}+3 \mathrm{sm}+5 \mathrm{st}+2 \mathrm{a}$ and 20 mi for females (Figure 1f,h). A remarkable heteromorphism was identified in both Spilotes species, evidencing the presence of a heteromorphic ZZ/ZW sex chromosome system. The sex chromosomes in both species correspond to the fourth pair. However, $\mathrm{Z}$ chromosomes are $\mathrm{m}$ and $\mathrm{sm}$ in S. sulphureus and S.pullatus, respectively. In both species, the W chromosomes were highly degenerated and were found to be a and st chromosomes in S. sulphureus and S.pullatus, respectively. (Figure 1B,F).



Spilotes sulphureus

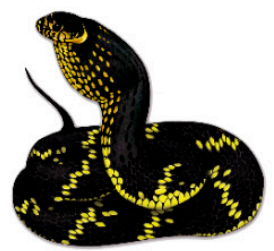

Spilotes pullatus
๙ Spilotes sulphureus

a

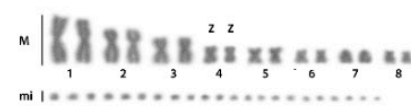

o



ऽี Spilotes pullatus
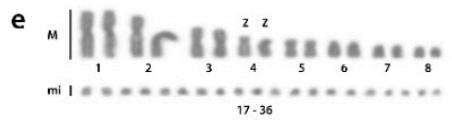

o

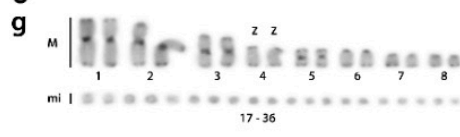

q
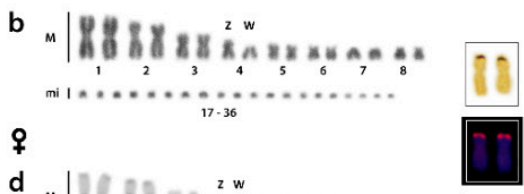

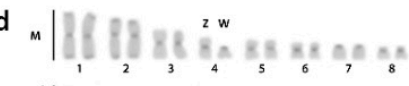

$17 \cdot 36$

q

f $1818188^{2}$

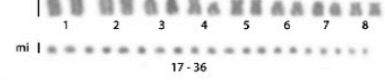

q

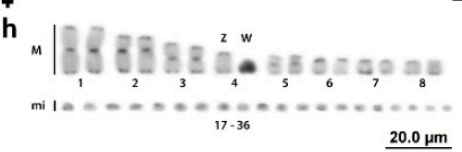

Figure 1. Karyotypes of Spilotes sulphureus $(\mathbf{A}, \mathbf{B})$ and Spilotes pullatus $(\mathbf{E}, \mathbf{F})$ in Giemsa-staining and C-banding $(\mathbf{C}, \mathbf{D}, \mathbf{G}, \mathbf{H})$, respectively, chromosomes showing the heteromorphism of the fourth pair in both females. Note the euchromatic and heterochromatic W chromosomes in S. sulphureus and S. pullatus, respectively $(\mathbf{D}, \mathbf{H})$. Highlighted in the boxes the mapping of nucleolar organizer regions (NORs) and rDNA 18S. Illustrations by Bruna Borges.

\subsection{Ag-NORs, $18 \mathrm{~S}$ rDNA, and C-Positive Heterochromatin}

Ag-NORs were located on the short arms of one pair of M (second pair) in S. sulphureus and in a pair of $\mathrm{mi}$ in S. pullatus. These sites were confirmed by the mapping of the $18 \mathrm{~S}$ rDNA sequences (Figure 1, boxed). The C-positive heterochromatin were found in all chromosomes, with a preferential location on the centromeric and telomeric regions in both males and females of the two Spilotes species. Interestingly, the W sex chromosome was not completely heterochromatic in S. sulphureus, showing only a few centromeric markings (Figure 1D). On the contrary, the W chromosome of S. pullatus was entirely heterochromatic (Figure $1 \mathrm{H}$ ). The microchromosomes showed only spread centromeric bandings (Figure 1C,D,G,H).

\subsection{Chromosomal Mapping of Microsatellite Motifs and (TTAGGG)n Sequences}

All five microsatellites repeat motifs used $(\mathrm{AC})_{15},(\mathrm{AG})_{15},(\text { ATCC })_{8},(\text { ATTC })_{8},(\mathrm{GATA})_{8}$ showed hybridization signals on chromosomes of both Spilotes species. The $(\mathrm{AC})_{15}$ motifs were hybridized in practically all chromosomes of $S$. sulphureus, including strong signals on the whole W chromosome, whereas S. pullatus showed signals only on the short arms of the second pair (Figure 2A, boxed). The $(\mathrm{AG})_{15}$ motifs showed different patterns of hybridization for the two species, being S. sulphureus 
with markings in centromeric position on the first and fourth pairs and telomeric signals in the W chromosome, whereas $S$. pullatus have bitelomeric markings in all chromosomes, with a great accumulation in the centromeric position of the second pair and in the long arms of the $W$ sex chromosome, being only bitelomeric in the Zs (Figure $2 \mathrm{~B}$ and Highlighted in the boxes). The (ATCC) 8 , $(\text { ATTC })_{8}$ and $(\text { GATA })_{8}$ repeats were hybridized only on the $W$ chromosomes, however, with different patterns for two species. In $S$. sulphureus the (ATTC) ${ }_{8}$ repeats were hybridized on to the whole W, with a diffuse pattern, the (GATA) $)_{8}$ showed two markings in the end of long arms, whereas, interestingly, the $(\text { ATTC })_{8}$ repeats were absent in the W (Figure 2, boxed). For S. pullatus the (ATCC) 8 repeats were strongly hybridized only on the long arms of the $W$ chromosome. Both (GATA) 8 and (ATCC) 8 repeats showed the same pattern with signals only in the long arms (Figure 2, boxed).

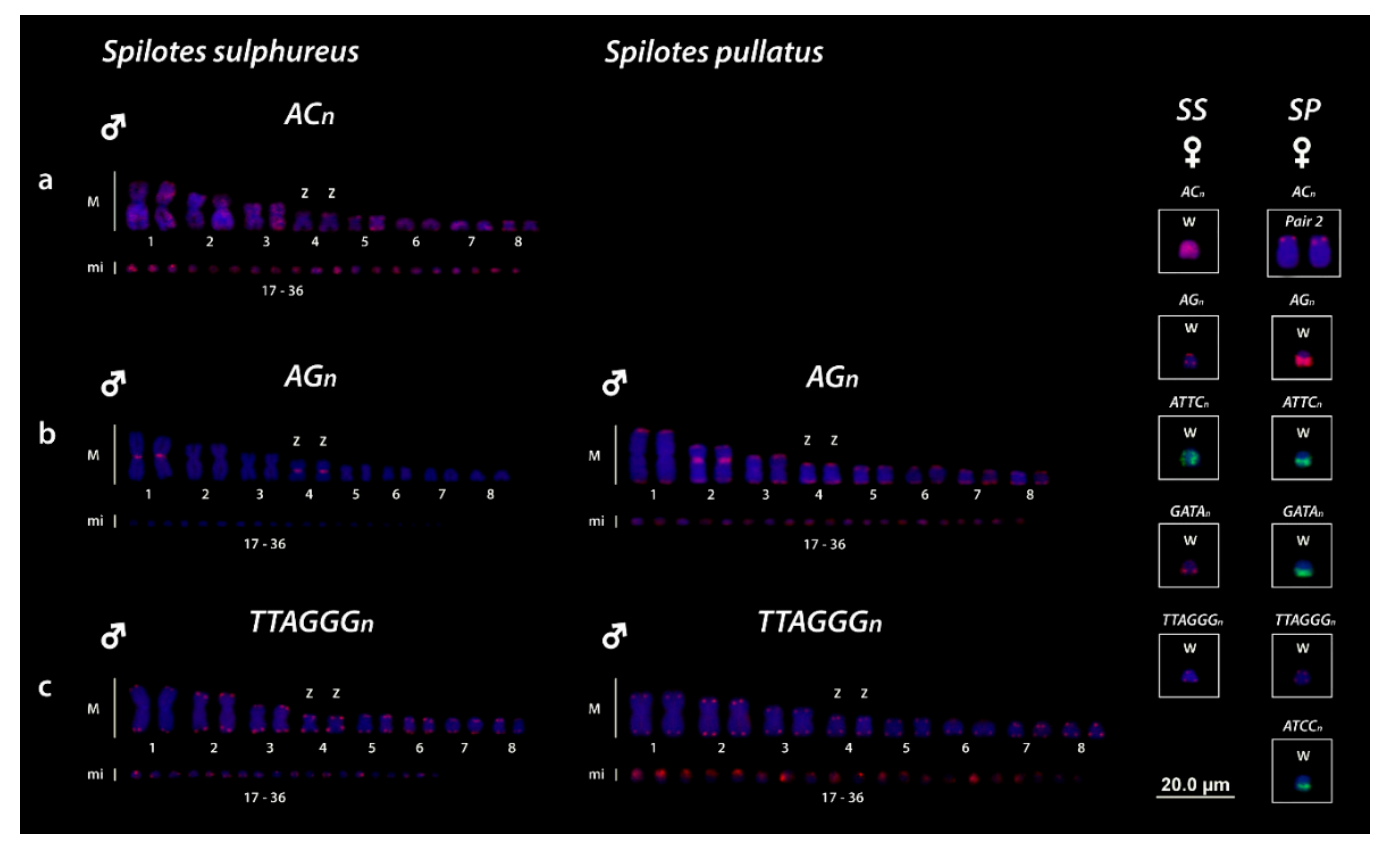

Figure 2. Mapping of (AC)n (a), (AG)n (b) and (TTAGGG)n (c) on the chromosomes of S. sulphureus and S. pullatus. $\mathrm{AC}_{\mathrm{n}}$ repeats were evidenced on the second pair of both species and on both $\mathrm{Z}$ and $\mathrm{W}$ chromosomes of SS but absent in the $\mathrm{Z}$ and $\mathrm{W}$ chromosomes of SP (a and highlighted in the boxes). Highlighted in the boxes are the differential accumulation of SSR repeats on the W sex chromosomes for SS (S. sulphureus) and SP (S. pullatus).

Telomeric repeats (TTAGGG) 5 revealed terminal hybridization signals in all chromosomes of the complement, without any interstitial sequences (ITSs), even in the W chromosomes for both Spilotes species (Figure 2C, boxed).

\subsection{Comparative Genomic Hybridization (CGH)}

In the first set of experiments, we performed intraspecific comparisons, with special emphasis on the molecular composition of the ZW sex chromosomes of S. pullatus. When hybridized to S. pullatus female metaphases, the hybridization of the gDNA from both male and female produced intense hybridization signals on macro and micro chromosomes, collocating primarily with C-banded regions. Concerning the sex chromosomes, the merged images revealed that sequences from both sexes are shared on terminal region of the $\mathrm{Wq}$ arms, whereas female-specific sequences were concentrated in the pericentromeric region, thus identifying a female-specific region on the $\mathrm{W}$ chromosome (Figure 3A). No hybridization signals were observed on the $Z$ chromosome (Figure 3B), which might be due to the low shared content of repetitive sequences on $\mathrm{Z}$. Consecutively, CGH experiments confirmed the pattern. 


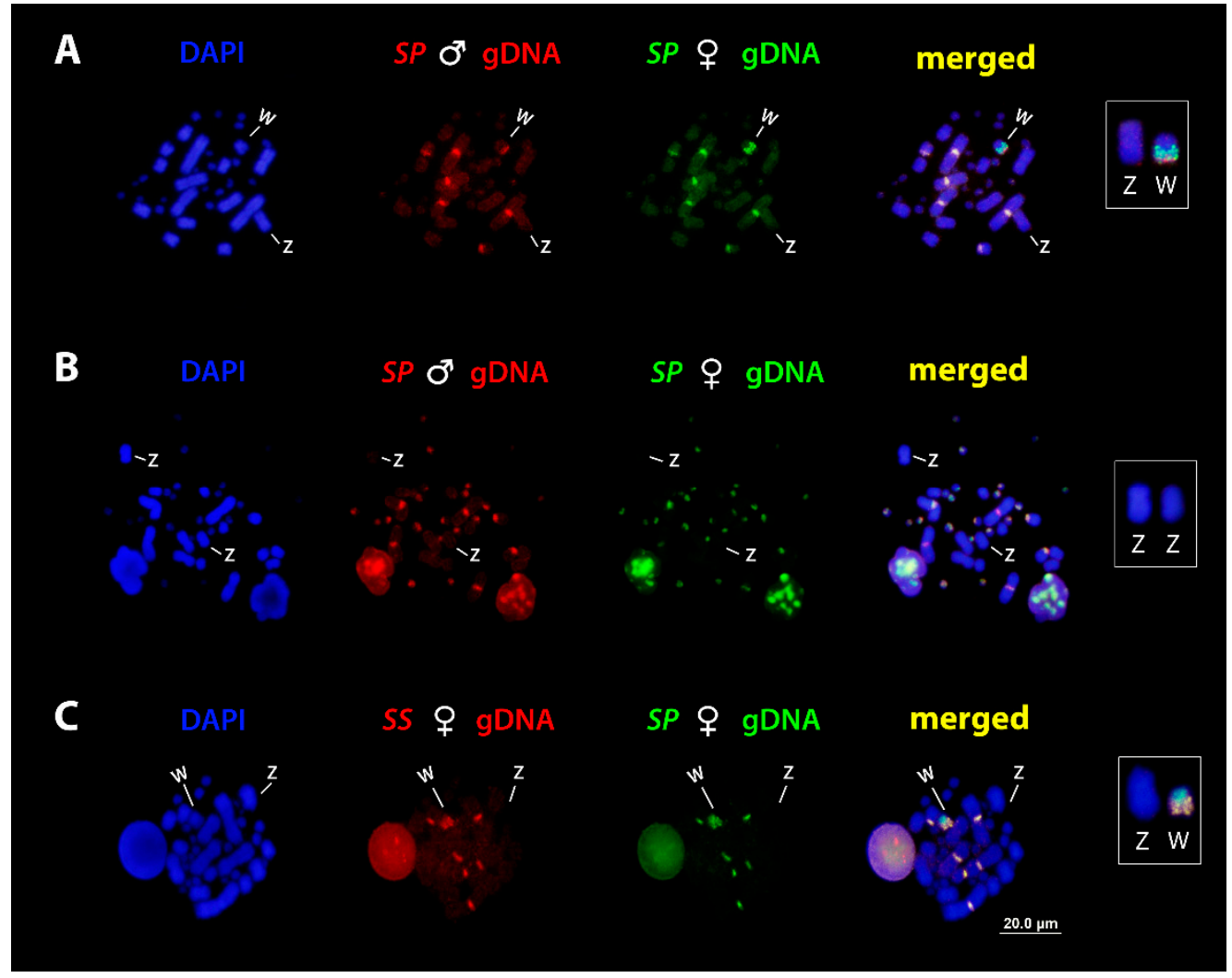

Figure 3. Mitotic chromosome spreads of S. pullatus after comparative genomic hybridization (CGH) procedures and cross-Species comparison. Male and female-derived genomic probes from S. pullatus mapped against female (A) and male (B) chromosomes of S. pullatus. (C) Female-derived genomic probes from S. pullatus (SP) and S. sulphureus (SS) mapped against female chromosomes of S. pullatus. The common genomic regions are identified as yellow. Please note the shared regions of the $\mathrm{W}$ chromosomes in both species and absence of signals on $\mathrm{Z}$ chromosome. $\mathrm{Z}$ and $\mathrm{W}$ sex chromosomes are boxed.

In the second set of experiments, we performed interspecific hybridization between both species. The results showed that these two species share conserved regions in their chromosomes (Pairs one, two, and seven), as well as with their W sex chromosomes, particularly on the long arms (Figure 3C). No hybridization signals were observed on $\mathrm{Z}$ chromosomes.

\section{Discussion}

\subsection{Cytotaxonomy in Spilotes Clade}

Different approaches (e.g., morphological and molecular data) have suggested that Spilotes, together with Phrynonax, share a most recent common ancestor, and comprise a monophyletic group $[2,5,18,55]$. They represent the most recently evolved clade of Caenophidian snakes and show a remarkable karyotype diversity ranging from different $2 n$ (36 to 38) and presence and absence or differentiated sex chromosomes [21,22]. In our study, we identified $2 \mathrm{n}=36$ chromosomes for a $S$. sulphureus, which differs from those found for S. sulphureus (= Pseustes sulphureus) female by Beçak and Beçak [22]. The karyotype of S. sulphureus formerly analyzed (locality of origin mentioned just as Brazil), had $2 \mathrm{n}=38$ chromosomes with $18 \mathrm{M}$ and $20 \mathrm{mi}$, which largely diverges from what we found for S. sulphureus from the Amazon region under analysis in this paper $(2 n=36,16 \mathrm{M}$ and $20 \mathrm{mi})$. In addition, we identified a well-differentiated ZW sex chromosome system, absent in $S$. sulphureus analyzed by Beçak and Beçak [22]. Such differences (regarding the $2 \mathrm{n}$ and presence/absence of well-differentiated sex chromosomes) certainly calls into question the possibility that two different 
species were examined. However, given the limited sample sizes of each study, further investigation is warranted.

Chromosomal data for the S. pullatus group were only reported for S. pullatus anomalepis (o and †from Paraná and São Paulo States/South of Brazil) and S. pullatus maculatus (only ffrom São Paulo State/South of Brazil), variants of the same species [56]. They presented conserved karyotypes with $2 \mathrm{n}$ $=36(16 \mathrm{M}$ and $20 \mathrm{mi})$ and a ZW sex chromosome system [57], which is similar to those we found for both Spilotes species from Amazon region analyzed in this paper. However, the karyotype formulae and morphology of ZW chromosomes largely differ between the species analyzed previously [22,57] and the ones here analyzed (Figure 1). This highlights a notable chromosomal diversity within the Spilotes group regarding the chromosomal structure and presence/absence of well-differentiated sex chromosomes.

\subsection{Ribosomal Sequences in the Evolution of Snakes}

The rDNA sequences in Serpentes, more specifically the $18 \mathrm{~S}$ rDNA, are extremely variable among species of this suborder (e.g., Boidae, Viperidae, and Colubridae families) (see [36]). The presence of single hybridization signals on one pair of microchromosomes may be considered as a plesiomorphic feature for snakes representing ancestral lineage (e.g., Henophidia) [36,58]. On the other hand, hybridization signals on macrochromosomes, on multiple microchromosomes (or even on sex chromosomes) in advanced snakes (Caenophidian) are considered to be derived features [34,59-62]. This suggests that multiple events of chromosomal rearrangements involving this region may have occurred during karyotype evolution in snakes.

Although variable among different snake lineages, ribosomal sites seem to show an evolutionary trend in related groups, since, for instance, all Boidae snakes have rDNA located in one pair of microchromosomes [36,58]. However, in snakes from the Colubridae family (from those with known data), the $18 \mathrm{~S}$ rDNA is usually located in macrochromosomes [34,58], similar to the pattern here identified for S. sulphureus (Figure 1).

Unlike several vertebrate species, including Caenophidian snakes, no association of rDNA sequences and the sex chromosome of S. pullatus and S. sulphureus was identified [34,63-66]. This likely implies that NORs and rDNA sites located in two microchromosomes of $S$. pullatus, indeed represent an atypical condition for the Spilotes clade, as almost all Colubridae, analyzed up to now, present the NORs and 18S rDNA located on a pair of macrochromosomes (often on the 2nd). Perhaps this pattern could be the product of multiple chromosomal rearrangements involving this region and also could represent an ancestral condition for the clade composed by Spilotes and Phrynonax, once S. pullatus (signals on mi) occupy an ancestral position than S. sulphureus (signals on M) and Phrynonax species.

\subsection{Trends in the Role of Repetitive Sequences in the W Evolution of Caenophidian Snakes}

The accumulation of repetitive sequences, such as rDNA; retrotransposable elements, mini and microsatellites on sex chromosomes has been reported in several vertebrate species (e.g., [44,67-72]). Telomere motifs (TTAGGG)n and ITS, for example, have been identified in differentiated sex chromosomes of different groups as mammalian and reptiles [73-75] and even in homomorphic sex chromosomes of some Henophidian snakes [36]. In our research, no ITS were identified neither on the ZW sex chromosomes nor in the autosomes of both species analyzed. In contrast, Boid snakes (Henophidian) present multiple ITS in their chromosomes [36], which represents a common feature in several other reptile species (see [76]). This suggests that ITS indeed have an independent amplification throughout Serpentes lineages and are non-necessarily related to chromosomal fusions in all cases.

Microsatellites or simple sequence repeats (SSRs) are short extensions of tandemly repeated DNA sequences and shows several patterns of localization in eukaryotes. The SSRs are involved in the chromosomal structure and even in gene expression [77]. Such motifs have already been identified in sex chromosomes of several reptile species $[38,69,78,79]$ and its general association with sex chromosomes suggests that this feature is one of the likely mechanisms that led to their 
differentiation [69]. For instance, the (GATA $)_{n}$, component of banded krait minorsatellite $(B k m)$, is a typical microsatellite located in the $\mathrm{W}$ chromosomes of Caenophidian $[34,38,44,80,81]$. However, these sequences are not always confined to the $\mathrm{W}$ chromosomes, having been identified also on $\mathrm{Y}$ chromosomes in some other lineages, such as in lizards [71], as well as in autosomes of some fish species $[82,83]$. It has been suggested that $B \mathrm{~km}$ motifs play an important role in chromatin organization, being associated with transcription factors and formation of heterochromatin [82,84-87] and, hence, may have regulatory functions in the process of differentiation of sex chromosomes. The pattern of such $\mathrm{W}$-linked sequences (GATA) $)_{n}$ is frequently found in Caenophidian snakes $[37,38,40]$, but interestingly absent in ancestral lineages [88]. However, it is worth highlighting that microsatellites motifs have an evolutionary dynamic origin, differencing among distant groups [69,89], and even at in genera and species level.

SSRs are not exclusive of the sex chromosomes in reptiles, being frequently located also in the autosomes, similar to the scenario here found for $(\mathrm{AC})_{\mathrm{n}}$ and $(\mathrm{AG})_{\mathrm{n}}$ in both Spilotes species. Rovatsos et al. [71], for instance, identified accumulation of the (AC) $n$ motifs in both autosomes and sex chromosomes of Lialis species (Pygopodidae). Likewise, we identified (AG) $)_{\mathrm{n}}$ in both autosomes and sex chromosomes for S. sulphureus and a great accumulation in the W of S. pullatus (Figure 2). Nevertheless, the females showed a specific amplification for the $(\mathrm{AG})_{\mathrm{n}}$ in their $\mathrm{W}$ sex chromosomes. Similarly, Matsubara et al. [69] evidenced that (AG) ${ }_{n}$ motif is clearly associated with sex differentiation in a turtle species of the family Chelidae. Thus, the presence of microsatellites motifs in the $\mathrm{W}$ chromosomes of phylogenetic divergent groups led us to suppose that these sequences might have some role in the process of the sex chromosome differentiation.

\subsection{Stability of Gene Content in Snakes Sex Chromosomes}

Different approaches using cytogenetic and molecular tools have provided novel information regarding the genetic content and evolution of sex chromosomes in vertebrates (see $[29,41])$ and independent pathways for the origin of sex chromosomes between reptiles and other vertebrate groups have been proposed $[33-35,90]$. However, sex chromosomes in snakes exhibit relative stability among lineages [33,39].

Although the content of repetitive sequences in the $\mathrm{W}$ sex chromosome is stable across Caenophidian species [38], our data, using mapping of several SSRs and C-banding, showed a divergent scenario for the two closely related Colubridae species here analyzed. This could suggest that $\mathrm{W}$ chromosome and heterochromatin in Caenophidian snakes are indeed dynamic regarding repetitive sequences content. Moreover, this could explain the high diversity of morphologies of W's along the evolution of snakes [22,91] and their different stages of evolution with homomorphy, ranging from completely heterochromatic and non-heterochromatic Ws (Figure 4), being the non-heterochromatic W of S. sulphureus, a novel finding in Caenophidian snakes.

These findings demonstrate the inherent dynamics of the repetitive DNAs, as well as the pathways that shape the evolutionary history of the sex chromosomes, even among closely related species. This trend for the $\mathrm{W}$ chromosome differentiation was already reported for other animal groups, such as fishes [92,93], birds [94], lizards [71], and snakes [38].

Although sharing the same content of some repetitive sequences of the $\mathrm{W}$ chromosomes (e.g., AG; ATTC; GATA; Telomere) and with differences in the pattern of accumulation of heterochromatin, the W chromosomes of S. pullatus and S. sulphureus are very similar, with a subtle divergence in the morphology, being st and a in S. pullatus and S. sulphureus, respectively. Indeed, it is intriguing to find a non-heterochromatic W chromosome in S. sulphureus, once the heterochromatinization and accumulation of $B \mathrm{~km}$ sequences in $\mathrm{W}$ chromosomes arose in the early Caenophidian snakes $[40,88]$. Therefore, we can conclude that: (i) The accumulation of Bkm repeats, and, consequently, heterochromatinization of $\mathrm{W}$ is not a general rule for Caenophidian snakes, or alternatively, (ii) the $\mathrm{W}$ chromosomes of $S$. sulphureus represents an exception to this scenario. The real meaning for a non-stability of sex chromosomes in the most advanced clade of Caenophidians could be 
explained by a possibly recent and independent evolution of sex chromosomes ongoing in S. sulphureus. Sex chromosomes can evolve independently between closely related species $[27,78,95,96]$, which seems to be the case of Spilotes clade, where the species differ from each other by the SSRs content in both Z and $\mathrm{W}$, presence/absence of well-differentiated sex chromosomes, and euchromatic and heterochromatic Ws. The Z chromosomes, on the other hand, are sm and $\mathrm{m}$ in S. pullatus and S. sulphureus, respectively (Figures 1 and 4), being the $Z$ chromosome from the former, being very similar to the one present in Ptyas (Figure 4). These differences could be explained by the rapid and independent evolution of $Z$ chromosomes in relation to the autosomes [97,98], a phenomenon also already seen in the Ptyas' $\mathrm{Z}$ chromosomes [99].
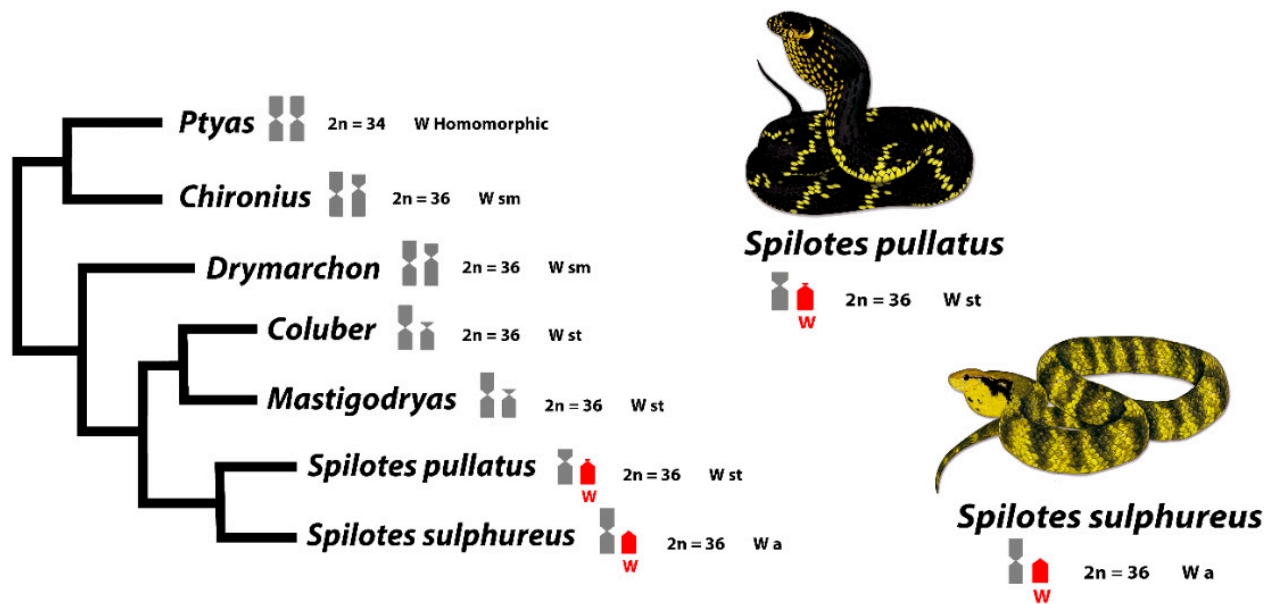

Figure 4. Truncated phylogeny of Caenophidian snakes including Spilotes and closely related species showing patterns of sex chromosomes differentiation. The red color highlights the shared W chromosome sequences between species revealed by CGH. Tree topology is adapted from [55]. The sm (submetacentric), st (subtelocentric), and a (acrocentric) corresponds to the W's morphologies. Illustrations by Bruna Borges.

Among the phylogenetically related groups to Spilotes, an apparent degeneration of the W's short arms is evident. In Ptyas, for instance, both Z and W chromosomes are homomorphic [91,100], whereas the $\mathrm{W}$ is sm in Chironius and Drymarchon, with a similar size to the Z [52]. In Coluber and Mastigodryas, the $\mathrm{W}$ is st, smaller than $Z[57,101]$. By contrast, degenerated st and a $\mathrm{W}$ chromosome are present in Spilotes (Figure 4). The Ptyas' W chromosome is homomorphic but presents BKM repeats only on the W chromosome (like S. pullatus and S. sulphureus), with no signals in males [37]. Also, specific female sequences (e.g., WAC9, CTNNB1 and CTNNB1W) were identified in this genus [102]. Even being non-stable in its content of sequences, morphology, and different stages of heterochromatinization, the $\mathrm{W}$ chromosomes, somehow, have a common evolutionary history among Caenophidian species. Therefore, it seems that the $\mathrm{W}$ chromosomes tend to eliminate sequences from the short arms (suggesting that the sex-determining genes are present in the long arms). This scenario opens the opportunity for fine-scale analysis of sex chromosome sequences in this group, which certainly will assist in discovering the mechanisms of ZW sex chromosome evolution in snakes.

\subsection{Origin and Evolution of Sex Chromosomes in Caenophidian Snakes}

Comparative cytogenetics revealed that at least 11 genes are shared on the $\mathrm{Z}$ chromosomes among ancestral (Henophidian) and advanced snakes (Caenophidian) [33], suggesting an evolutionary conservatism $[35,39]$. However, our data highlights the evolution and origin of sex chromosomes in our study species. Based on our data we propose two alternative scenarios: Scenario 1. ZW chromosomes of S. pullatus and S. sulphureus evolved from a common ancestral autosomal pair. The proto $Z$ chromosomes have largely retained its ancestral morphology, except for a segmental deletion of 
the proximal region of the short arms in S. pullatus, while proto $\mathrm{W}$ chromosomes have undergone gradual gene loss and degeneration from the short arms, subsequently losing the entire short arms of W chromosomes in S. pullatus and S. sulphureus. The W chromosomes subsequently accumulated and amplified repetitive sequences, facilitating suppression of recombinations between $\mathrm{Z}$ and $\mathrm{W}$ chromosomes (Figures 4 and 5a).

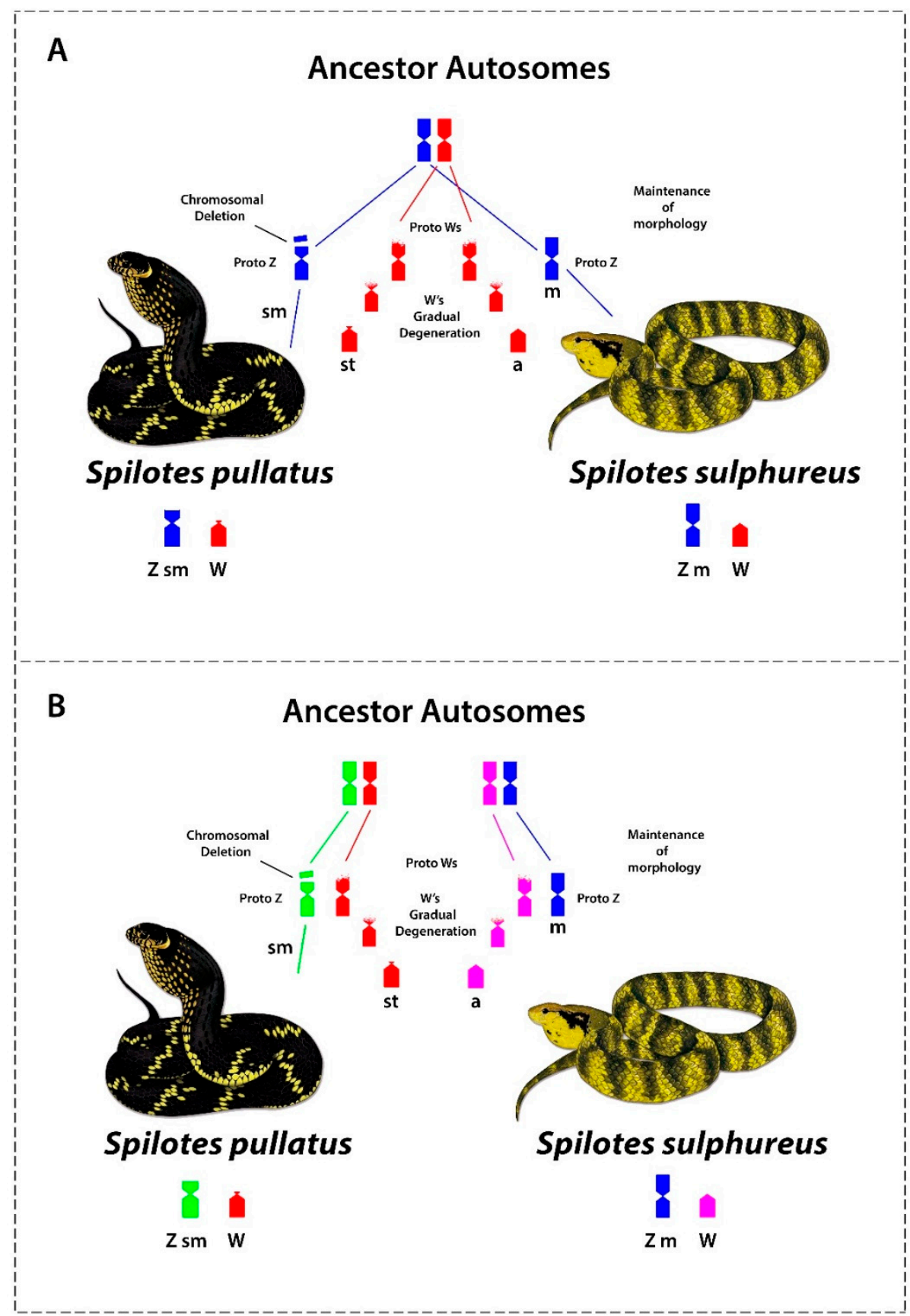

Figure 5. Different possible scenarios of the evolution of the $\mathrm{Z}$ and $\mathrm{W}$ chromosomes in Spilotes. (A) Where the $\mathrm{Z}$ and $\mathrm{W}$ chromosomes in the two Spilotes species share ancestry and (B) where the Spilotes species have evolved their $\mathrm{Z}$ and $\mathrm{W}$ independently from different autosome pairs. In this scenario, the similarity of sequences revealed by $\mathrm{CGH}$ is result of an evolutionary convergent acquisition of repetitive sequences on $\mathrm{W}$. 
Scenario 2. The $\mathrm{Z}$ and $\mathrm{W}$ chromosomes may have evolved independently from multiple ancestral autosomal pairs. The proto $\mathrm{Z}$ and $\mathrm{W}$ chromosomes have undergone similar evolutionary changes, as in scenario 1. However, the apparent homologies between the W chromosomes of S. pullatus and $S$. sulphureus may likely be result of accumulation and amplification of similar repetitive sequences on the $\mathrm{W}$ chromosomes in both species via convergence (Figure $5 b$ ).

However, further studies are required to conclusively interpret which of the above scenarios is correct. To conclusively demonstrate homologies between $\mathrm{ZW}$ chromosomes between these species, evidence from the sequence level comparison will be required. For instance, this can be achieved by microdissecting $\mathrm{Z}$ and $\mathrm{W}$ chromosomes and subsequent cross species painting to demonstrate $\mathrm{Z}$ chromosomes homologies and sequencing microdissected sex chromosomes to infer synteny.

Author Contributions: P.V. designed the study and initial structure. P.V. and B.J.A. performed laboratory experiments and all authors analyzed and interpreted the data. P.V wrote the manuscript with contributions from T.E., M.B.C., B.J.A. and E.F.

Funding: PFV is funded by Coordenação de Aperfeiçoamento de Pessoal de Nível Superior CAPES (Grant Number: 88881.190036/2018-01). TE is supported in part by an Australian Research Council Discovery Grant DP170101147. MBC is funded by Conselho Nacional de Desenvolvimento Científico e Tecnológico (CNPq) (Grant number: 302449/2018-3) and CAPES/Alexander von Humboldt (Grant number: 88881.136128/2017-01). EF is funded by Center for Studies on Adaptations of Aquatic Biota of the Amazon (Centro de Estudos de Adaptações da Biota Aquática da Amazônia-ADAPTA), Projects (Pronex/FAPEAM/CNPq 003/2009), MCT/CNPq/MEC/CAPES/FNDCT-Cross Action/FAPs No. 47/2010-BioPHAM Network and the CAPES-Pro-Amazon Program: Biodiversity and Sustainability, Public Notice No. 047/2012.

Acknowledgments: We are greatful to the Institute Chico Mendes of Conservation of Biodiversity (ICMBio: Instituto Chico Mendes de Conservação da Biodiversidade-ICMBio/SISBIO) for theauthorization for animal collection (license number 45275). We are also grateful to the Animal Husbandry of the National Institute of Amazonian Research (Biotério Central-INPA) and Isaías José dos Reis (ICMBio) by all logistical support, Milena Almeida from the Amazonian Center for Herpetology (Centro Amazônico de Herpetologia); Célio Lima Jucá and Maria de Fátima Ferreira for all support in the field activities.

Conflicts of Interest: The authors declare no conflict of interest.

Ethics Statement: All procedures were performed under rules of Ethics Committee of the National Institute of Amazonian Research (Permission number: 018/2017).

\section{References}

1. Uetz, P.; Freed, P.; Hošek, J. (Eds.) The Reptile Database. Available online: http://www.reptile-database.org (accessed on 26 November 2018).

2. Dowling, H.G.; Duellman, W.E. Systematic Herpetology: A Synopsis of Families and Higher Categories; Herpetological Information Search System Publications: New York, NY, USA, 1978.

3. Vidal, N.; Dewynter, M.; Gower, D.J. Dissecting the major American snake radiation: A molecular phylogeny of the Dipsadidae Bonaparte (Serpentes, Caenophidia). C. R. Biol. 2010, 333, 48-55. [CrossRef]

4. Pyron, R.A.; Burbrink, F.T.; Colli, G.R.; Montes de Oca, A.N.; Vitt, L.J.; Kuczynski, C.A.; Wiens, J.J. The phylogeny of advanced snakes (Colubroidea), with discovery of a new subfamily and comparison of support methods for likelihood trees. Mol. Phylogenet. Evol. 2011, 58, 329-342. [CrossRef]

5. Pyron, R.A.; Burbrink, F.T.; John, J. A phylogeny and revised classification of Squamata, including 4161species of lizards and snakes. BMC Evol. Biol. 2013, 13, 93. [CrossRef] [PubMed]

6. Pyron, R.A.; Hendry, C.R.; Chou, V.M.; Lemmon, E.M.; Lemmon, A.R.; Burbrink, F.T. Effectiveness of phylogenomic data and coalescent species tree methods for resolving difficult nodes in the phylogeny of advanced snakes (Serpentes: Caenophidia). Mol. Phylogenet. Evol. 2014, 81, 221-231. [CrossRef] [PubMed]

7. Duellman, W.E. Patterns of species diversity in anuran amphibians in the American tropics. Ann. Mo. Bot. Gard. 1988, 75, 79-104. [CrossRef]

8. Duellman, W.E. Hylid Frogs of Middle America, 2nd ed.; SSAR: Ithaca, NY, USA, 2001.

9. Bergmann, P.J.; Russell, A.P. Systematics and biogeography of the widespread Neotropical gekkonid genus Thecadactylus (Squamata), with the description of a new cryptic species. Zool. J. Linn. Soc. 2007, 149, 339-370. [CrossRef] 
10. Ribas, C.C.; Aleixo, A.; Nogueira, A.C.; Miyaki, C.Y.; Cracraft, J. A palaeobiogeographic model for biotic diversification within Amazonia over the past three million years. Proc. R. Soc. Lond. B 2012, 279, 681-689. [CrossRef]

11. Cunha, O.R.; Nascimento, F.P. Ofídios da Amazônia. X - As Cobras da Região Leste do Pará; Publicacoes Avulsas; Museu Paraense Emilio Goeldi: Belem, Portugal, 1978; Volume 31, pp. 1-218.

12. Perez, S.; Moreno, A.G. Ofidios de Colombia; Museo Regionale di Scienze Naturali di Torino: Torino, Italy, $1988 ; 517 p$.

13. De Fraga, R.; Lima, A.P.; Prudente, A.L.C.; Magnusson, W.E. Guia de Cobras da Região de Manaus-Amazônia Central; Editora INPA: Manaus, Brazil, 2013; 303p.

14. Dixon, J.R.; Soini, P. The Reptiles of the Upper Amazon Basin, Iquitos Region, Peru. II. Crocodilians, Turtles and Snakes; Contributions in Biology and Geology; Milwaukee Public Museum: Milwaukee, WI, USA, 1977; pp. 1-71.

15. Chippaux, J.P. Les Serpents de la Guyane Française: Faune Tropicale XXVII; IRD (Institut de recherche pour le développement): Paris, France, 1986; 167p.

16. Wallach, V.; Williams, K.L.; Boundy, J. Snakes of the World: A Catalogue of Living and Extinct Species; CRC Press: Boca Raton, FL, USA, 2014. [CrossRef]

17. Fitzinger, L. Systema Reptilium, Fasciculus Primus: Amblyglossae; Braumüller et Seidel: Wien, Austria, 1843; $106 \mathrm{p}$.

18. Jadin, R.C.; Burbrink, F.T.; Rivas, G.A.; Vitt, L.J.; Barrio-Amoros, C.L.; Guralnick, A.P. Finding arboreal snakes in an evolutionary tree: Phylogenetic placement and systematic revision of the Neotropical birdsnakes. J. Zool. Syst. Evol. Res. 2013, 52, 257-264. [CrossRef]

19. Olmo, E.; Signorino, G. Chromorep: A Reptile Chromosomes Database. 2005. Available online: http: //chromorep.univpm.it/ (accessed on 30 March 2018).

20. Oguiura, N.; Ferrarezzi, H.; Batistic, R.F. Cytogenetics and molecular data in snakes: A phylogenetic approach. Cytogenet. Genome Res. 2009, 127, 128-142. [CrossRef]

21. Beçak, W.; Beçak, M.L.; Nazareth, H.R.S.; Ohno, S. Close karyological kinship between the reptilian suborder Serpentes and the class Aves. Chromosoma 1964, 15, 606-617. [CrossRef]

22. Beçak, W.; Beçak, M.L. Cytotaxonomy and chromosomal evolution in Serpentes. Cytogenetics 1969, 8, $247-262$. [CrossRef] [PubMed]

23. Rovatsos, M.; Johnson Pokorná, M.; Kratochvíl, L. Differentiation of sex chromosomes and karyotype characterisation in the dragonsnake Xenodermus javanicus (Squamata: Xenodermatidae). Cytogenet. Genome Res. 2015, 147, 48-54. [CrossRef]

24. Falcione, C.; Hernando, A.B.; Di Pietro, D.O. Karyotypes of four species of Xenodontini snakes (Serpentes) and implications for taxonomy. Contrib. Zool. 2016, 85, 265-273. [CrossRef]

25. Patawang, I.; Tanomtong, A.; Kaewmad, P.; Chuaynkern, Y.; Duengkae, P. New record on karyological analysis and first study of NOR localization of parthenogenetic brahminy blind snake, Ramphotyphlops braminus (Squamata, Typhlopidae) in Thailand. Nucleus 2016, 59, 61-66. [CrossRef]

26. Ohno, S. Sex Chromosomes and Sex-Linked Genes; Springer: New York, NY, USA, 1967.

27. Ezaz, T.; Sarre, S.D.; O’Meally, D.; Graves, J.A.; Georges, A. Sex chromosome evolution in lizards: Independent origins and rapid transitions. Cytogenet. Genome Res. 2009, 127, 249-260. [CrossRef] [PubMed]

28. Rhen, T.; Schroeder, A. Molecular mechanisms of sex determination in reptiles. Sex Dev. 2010, 4, 16-28. [CrossRef] [PubMed]

29. Ezaz, T.; Srikulnath, K.; Graves, J.A.M. Origin of amniote sex chromosomes: An ancestral super-sex chromosome, or common requirements? J. Hered. 2017, 108, 94-105. [CrossRef] [PubMed]

30. Alam, S.; Sarre, S.; Gleeson, D.; Georges, A.; Ezaz, T. Did Lizards Follow Unique Pathways in Sex Chromosome Evolution? Genes 2018, 9, 239. [CrossRef]

31. Pokorna, M.; Kratochvíl, L. Phylogeny of sex-determining mechanisms in squamate reptiles: Are sex chromosomes an evolutionary trap? Zool. J. Linn. Soc. 2009, 156, 168-183. [CrossRef]

32. Gamble, T.; Castoe, T.A.; Nielsen, S.V.; Banks, J.L.; Card, D.C.; Schield, D.R.; Schuett, G.W.; Booth, W. The discovery of $\mathrm{XY}$ sex chromosomes in a boa and report the discovery of $\mathrm{XY}$ sex chromosomes in a boa and python. Curr. Biol. 2017, 27, 1-6. [CrossRef] 
33. Matsubara, K.; Tarui, H.; Toriba, M.; Yamada, K.; Nishida-Umehara, C.; Agata, K.; Matsuda, Y. Evidence for different origin of sex chromosomes in snakes, birds, and mammals and step-wise differentiation of snake sex chromosomes. PNAS 2006, 103, 18190-18195. [CrossRef] [PubMed]

34. O'Meally, D.; Patel, H.R.; Stiglec, R.; Sarre, S.D.; Georges, A.; Graves, J.A.M.; Ezaz, T. Non-homologous sex chromosomes of birds and snakes share repetitive sequences. Chromosome Res. 2010, 18, 787-800. [CrossRef]

35. Vicoso, B.; Emerson, J.J.; Zektser, Y.; Mahajan, S.; Bachtrog, D. Comparative sex chromosome genomics in snakes: Differentiation, evolutionary strata, and lack of global dosage compensation. PLoS Biol. 2013, 11, e1001643. [CrossRef] [PubMed]

36. Viana, P.F.; Ribeiro, L.B.; Souza, G.M.; Chalkidis, H.d.M.; Gross, M.C.; Feldberg, E. Is the Karyotype of Neotropical Boid Snakes Really Conserved? Cytotaxonomy, Chromosomal Rearrangements and Karyotype Organization in the Boidae Family. PLoS ONE 2016, 11, e0160274. [CrossRef]

37. Singh, L.; Purdom, I.F.; Jones, K.W. Sex chromosome associated satellite DNA: Evolution and conservation. Chromosoma 1980, 79, 137-157. [CrossRef] [PubMed]

38. Augstenová, B.; Mazzoleni, S.; Kratochvíl, L.; Rovatsos, M. Evolutionary dynamics of the W chromosome in caenophidian snakes. Genes 2017, 9, 5. [CrossRef] [PubMed]

39. Rovatsos, M.; Vuki'c, J.; Lymberakis, P.; Kratochvíl, L. Evolutionary stability of sex chromosomes in snakes. Proc. R. Soc. B Biol. Sci. 2015, 282, 20151992. [CrossRef]

40. Matsubara, K.; Nishida, C.; Matsuda, Y.; Kumazawa, Y. Sex chromosome evolution in snakes inferred from divergence patterns of two gametologous genes and chromosome distribution of sex chromosome-linked repetitive sequences. Zool. Lett. 2016, 2, 19. [CrossRef] [PubMed]

41. Deakin, J.E.; Ezaz, T. Understanding the Evolution of Reptile Chromosomes through Applications of Combined Cytogenetics and Genomics Approaches. Cytogenet. Genome Res. 2019. [CrossRef] [PubMed]

42. Carvalho, P.C.; de Oliveira, E.A.; Bertollo, L.A.C.; Yano, C.F.; Oliveira, C.; Decru, E.; Jegede, O.I.; Hatanaka, T.; Liehr, T.; Al-Rikabi, A.B.H.; et al. First chromosomal analysis in Hepsetidae (Actinopterygii, Characiformes): Insights into relationship between African and Neotropical fish groups. Front. Genet. 2017, 8, 203. [CrossRef]

43. Hatanaka, T.; De Oliveira, E.A.; Ráb, P.; Yano, C.F.; Bertollo, L.A.; Ezaz, T.; Jegede, O.O.I.; Liehr, T.; Olaleye, V.F.; Cioffi, M.d.B. First chromosomal analysis in Gymnarchus niloticus (Gymnarchidae: Osteoglossiformes): Insights into the karyotype evolution of this ancient fish order. Biol. J. Linn. Soc. 2018, 125, 83-92. [CrossRef]

44. Singchat, W.; O'Connor, R.E.; Tawichasri, P.; Suntronpong, A.; Sillapaprayoon, S.; Suntrarachun, S.; Muangmai, N.; Baicharoen, S.; Peyachoknagul, S.; Chanhome, L.; et al. Chromosome map of the Siamese cobra: Did partial synteny of sex chromosomes in the amniote represent "a hypothetical ancestral super-sex chromosome" or random distribution? BMC Genomics 2018, 19, 939. [CrossRef] [PubMed]

45. Viana, P.F.; Ribeiro, L.B.; Lima, T.; de Carvalho, V.T.; Vogt, R.C.; Gross, M.C.; Feldberg, E. An optimized protocol for obtaining mitotic chromosomes from cultured reptilian lymphocytes. Nucleus 2016, 59, 1-5. [CrossRef]

46. Sumner, A.T. A simple technique for demonstrating centromeric heterochromatin. Exp. Cell Res. 1972, 75, 204-206. [CrossRef]

47. Howell, W.M.; Black, D.A. Controlled silver staining of nucleolus organizer regions with a protective colloidal developer: A 1-step method. Experientia 1980, 36, 1014-1015. [CrossRef] [PubMed]

48. Gross, M.C.; Schneider, C.H.; Valente, G.T.; Porto, J.I.R.; Martins, C.; Feldberg, E. Variability of $18 S$ rDNA locus among Symphysodon fishes: Chromosomal rearrangements. J. Fish Biol. 2010, 76, 1117-1127. [CrossRef] [PubMed]

49. Ijdo, J.W.; Wells, R.A.; Baldini, A.; Reeders, S.T. Improved telomere detection using a telomere repeat probe (TTAGGG)n generated by PCR. Nucleic Acids Res. 1991, 19, 4780. [CrossRef]

50. Kubat, Z.; Hobza, R.; Vyskot, B.; Kejnovsky, E. Microsatellite accumulation in the Y chromosome of Silene latifolia. Genome 2008, 51, 350-356. [CrossRef]

51. Pinkel, D.; Straume, T.; Gray, J. Cytogenetic analysis using quantitative, high sensitivity, fluorescence hybridization. Proc. Natl. Acad. Sci. USA 1986, 83, 2934-2938. [CrossRef] [PubMed]

52. Zwick, M.S.; Hanson, R.E.; Islam-Faridi, M.H.; Stelly, D.M.; Wing, R.A.; Price, H.J.; McKnight, T.D. A rapid procedure for the isolation of C0t-1 DNA from plants. Genome 1997, 40, 138-142. [CrossRef] [PubMed]

53. Symonová, R.; Sember, A.; Majtánová, Z.; Ráb, P. Characterization of fish genomes by GISH and CGH. In Fish Cytogenetic Techniques. Ray-Fin Fishes and Chondrichthyans; Ozouf-Costaz, C., Pisano, E., Foresti, F., Almeida Toledo, L.F., Eds.; CCR Press: Boca Raton, FL, USA, 2015; pp. 118-131. 
54. Levan, A.; Fredga, K.; Sandberg, A.A. Nomenclature for centromeric position on chromosomes. Hereditas 1964, 52, 201-220. [CrossRef]

55. Figueroa, A.; McKelvy, A.D.; Grismer, L.L.; Bell, C.D.; Lailvaux, S.P. A species-level phylogeny of extant snakes with description of a new colubrid subfamily and genus. PLoS ONE 2016, 11, e0161070. [CrossRef] [PubMed]

56. Abe, A.S.; Fernandes, W. Polymorphism in Spilotes pullatus anomalepis Bocourt (Reptilia, Serpentes: Colubridae). J. Herpetol. 1977, 11, 98-100. [CrossRef]

57. Beçak, W. Constituição cromossômica e mecanismo de determinação do sexo em ofídios sul americanos. I. Aspectos cariotípicos. Mem Inst Butantan 1965, 32, 37-78. [PubMed]

58. Porter, C.A.; Hamilton, M.J.; Sites, J.W., Jr.; Baker, R.J. Location of ribosomal DNA in chromosomes of squamate reptiles: Systematic and evolutionary implications. Herpetologica 1991, 47, 271-280.

59. Camper, J.D.; Hanks, B. Variation in the nucleolus organizer region among New World snakes. J. Herpetol. 1995, 29, 468-471. [CrossRef]

60. Moreno, R.; Navarro, J.; Iturra, P.; Veloso, A. The karyotype of Philodryas chamissonis (Colubridae). Identification of nucleolar organizer regions (NOR) and sex chromosomes by banding methods. Rev. Bras. Genet. 1987, 10, 497-506.

61. Trajtengertz, I.; Beçak, M.L.; Ruiz, I.R.G. Ribosomal cistrons in Bothrops neuwiedi (Serpentes) subspecies from Brazil. Genome 1995, 38, 601-606. [CrossRef]

62. García, J.A.R.; Hernando, A. Standard karyotype and nucleolus organizer region of Neotropical blindsnake Typhlops brongersmianus (Serpentes: Typhlopidae). Acta Herpetol. 2007, 2, 117-120.

63. Abramyan, J.; Ezaz, T.; Graves, J.A.M.; Koopman, P. Z and W sex chromosomes in the cane toad (Bufo marinus). Chromosome Res. 2009, 17, 1015-1024. [CrossRef]

64. Scacchetti, P.C.; Utsunomia, R.; Pansonato-Alves, J.C.; da Costa Silva, G.J.; Vicari, M.R.; Artoni, R.F.; Oliveira, C.; Foresti, F. Repetitive DNA Sequences and Evolution of ZZ/ZW Sex Chromosomes in Characidium (Teleostei: Characiformes). PLoS ONE 2015, 10, e0137231. [CrossRef] [PubMed]

65. Kawagoshi, T.; Uno, Y.; Nishida, C.; Matsuda, Y. The Staurotypus turtles and aves share the same origin of sex chromosomes but evolved different types of heterogametic sex determination. PLOS ONE 2014, 9, e105315. [CrossRef]

66. Viana, P.F.; Ezaz, T.; Marajó, L.; Ferreira, M.; Zuanon, J.; Cioffi, M.B.; Bertollo, L.A.C.; Feldberg, E. Genomic Organization of Repetitive DNAs and Differentiation of an XX/XY Sex Chromosome System in the Amazonian Puffer Fish, Colomesus asellus (Tetraodontiformes). Cytogenet. Genome Res. 2017, 153, 96-104. [CrossRef]

67. Cioffi, M.B.; Bertollo, L.A.C. Chromosomal distribution and evolution of repetitive DNAs in fish. In Repetitive DNAs; Garrido, R., Ed.; Karger: Basel, Switzerland, 2012.

68. Ezaz, T.; Azad, B.; O’Meally, D.; Young, M.J.; Matsubara, K.; Edwards, M.J.; Zhang, X.; Holleley, C.E.; Deakin, J.E.; Graves, J.A.M.; et al. Sequence and gene content of a large fragment of a lizard sex chromosome and evaluation of candidate sex differentiating gene R-spondin 1. BMC Genomics 2013, 14, 899. [CrossRef] [PubMed]

69. Matsubara, K.; O’Meally, D.; Azad, B.; Georges, A.; Sarre, S.D.; Graves, J.A.M.; Matsuda, Y.; Ezaz, T. Amplification of microsatellite repeat motifs is associated with the evolutionary differentiation and heterochromatinization of sex chromosomes in Sauropsida. Chromosoma 2016, 125, 111-123. [CrossRef] [PubMed]

70. Ferreira, M.; Garcia, C.; Matoso, D.A.; de Jesus, I.S.; Feldberg, E. A new multiple sex chromosome system X1X1X2X2/X1Y1X2Y2 in Siluriformes: Cytogenetic characterization of Bunocephalus coracoideus (Aspredinidae). Genetica 2016, 144, 591-599. [CrossRef] [PubMed]

71. Rovatsos, M.; Johnson Pokorná, M.; Altmanová, M.; Kratochvíl, L. Mixed-Up Sex Chromosomes: Identification of Sex Chromosomes in the X1X1X2X2/X1X2Y System of the Legless Lizards of the Genus Lialis (Squamata: Gekkota: Pygopodidae). Cytogenet Genome Res. 2016, 149, 282-289. [CrossRef] [PubMed]

72. Souza e Sousa, J.F.D.; Viana, P.F.; Bertollo, L.A.; Cioffi, M.B.; Feldberg, E. Evolutionary Relationships among Boulengerella Species (Ctenoluciidae, Characiformes): Genomic Organization of Repetitive DNAs and Highly Conserved Karyotypes. Cytogenet. Genome Res. 2017, 152, 194-203. [CrossRef]

73. Rovatsos, M.T.; Marchal, J.A.; Romero-Fernández, I.; Fernández, F.J.; Giagia-Athanosopoulou, E.B.; Sánchez, A. Rapid, independent, and extensive amplification of telomeric repeats in pericentromeric regions in karyotypes of arvicoline rodents. Chromosome Res. 2011, 19, 869-882. [CrossRef] 
74. Young, M.J.; O’Meally, D.; Sarre, S.D.; Georges, A.; Ezaz, T. Molecular cytogenetic map of the central bearded dragon, Pogona vitticeps (Squamata: Agamidae). Chromosome Res. 2013, 21, 361-374. [CrossRef]

75. Matsubara, K.; Uno, Y.; Srikulnath, K.; Matsuda, Y.; Miller, E.; Olsson, M. No interstitial telomeres on autosomes but remarkable amplification of telomeric repeats on theWsex chromosome in the sand lizard (Lacerta agilis). J. Hered. 2015, 106, 753-757. [CrossRef] [PubMed]

76. Rovatsos, M.; Kratochvíl, L.; Altmanová, M.; Johnson Pokorná, M. Interstitial telomeric motifs in squamate reptiles: When the exceptions outnumber the rule. PLoS ONE 2015, 10, e0134985. [CrossRef] [PubMed]

77. Hardman, N. Structure and function of repetitive DNA in eukaryotes. Biochem. J. 1986, 234, 1-11. [CrossRef] [PubMed]

78. Pokorná, M.; Kratochvíl, L.; Kejnovský, E. Microsatellite distribution on sex chromosomes at different stages of heteromorphism and heterochromatinization in two lizard species (Squamata: Eublepharidae: Coleonyx elegans and lacertidae: Eremias velox). BMC Genet. 2011, 12, 90. [CrossRef] [PubMed]

79. Matsubara, K.; Sarre, S.D.; Georges, A.; Matsuda, Y.; Graves, J.A.M.; Ezaz, T. Highly differentiated ZW sex microchromosomes in the Australian Varanus species evolved through rapid amplification of repetitive sequences. PLoS ONE 2014, 9, e95226. [CrossRef] [PubMed]

80. Ray-Chaudhuri, S.P.; Singh, L.; Sharma, T. Evolution of sex chromosomes and formation of W chromatin in snakes. Chromosoma 1971, 33, 239-251. [CrossRef] [PubMed]

81. Jones, K.W.; Singh, L. Snakes and evolution of sex chromosomes. TIG 1985, 1, 55-61. [CrossRef]

82. Pucci, M.B.; Barbosa, P.; Nogaroto, V.; Almeida, M.C.; Artoni, R.F.; Scacchetti, P.C.; Pansonato-Alves, J.C.; Foresti, F.; Moreira-Filho, O.; Vicari, M.R. Chromosomal Spreading of Microsatellites and (TTAGGG) n Sequences in the Characidium zebra and C. gomesi Genomes (Characiformes: Crenuchidae). Cytogenet. Genome Res. 2016, 149, 182-190. [CrossRef]

83. Pucci, M.B.; Nogaroto, V.; Bertollo, L.A.C.; Moreira-Filho, O.; Vicari, M.R. The karyotypes and evolution of ZZ/ZW sex chromosomes in the genus Characidium (Characiformes, Crenuchidae). Comp. Cytogenet. 2018, 12, 421-438. [CrossRef]

84. Singh, L.; Wadhwa, R.; Naidu, S.; Nagaraj, R.; Ganesan, M. Sex- and tissue-specific Bkm(GATA)-binding protein in the germcells of heterogametic sex. J. Biol. Chem. 1994, 269, 25321-25327.

85. Trainor, C.D.; Omichinski, J.G.; Vandergon, T.L.; Gronenborn, A.M.; Clore, G.M.; Felsenfeld, G. A palindromic regulatory site within vertebrate GATA-1 promoters requires both zinc fingers of the GATA-1 DNA-binding domain for high-affinity interaction. Mol. Cell Biol. 1996, 16, 2238-2247. [CrossRef] [PubMed]

86. Priyadarshini, P.; Murthy, B.S.; Nagaraju, J.; Singh, L. A GATA-binding protein expressed predominantly in the pupal ovary of the silkworm, Bombyx mori. Insect Biochem. Mol. Biol. 2003, 33, 185-195. [CrossRef]

87. Subramanian, S.; Mishra, R.K.; Singh, L. Genomewide analysis of Bkm sequences (GATA repeats): Predominant association with sex chromosomes and potential role in higher order chromatin organization and function. Bioinformatics 2003, 19, 681-685. [CrossRef] [PubMed]

88. Rovatsos, M.; Altmanová, M.; Johnson Pokorná, M.; Augstenová, B.; Kratochvíl, L. Cytogenetics of the Javan file snake (Acrochordus javanicus) and the evolution of snake sex chromosomes. J. Zool. Syst. Evol. Res. 2018, 56, 117-125. [CrossRef]

89. Adams, R.H.; Blackmon, H.; Reyes-Velasco, J.; Schield, D.R.; Card, D.C.; Andrew, A.L.; Waynewood, N.; Castoe, T.A. Microsatellite landscape evolutionary dynamics across 450 million years of vertebrate genome evolution. Genome 2016, 59, 295-310. [CrossRef] [PubMed]

90. O'Meally, D.; Ezaz, T.; Georges, A.; Sarre, S.D.; Graves, J.A.M. Are some chromosomes particularly good at sex? Insights from amniotes. Chromosome Res. 2012, 20, 7-19. [CrossRef] [PubMed]

91. Singh, L. Evolution of karyotypes in snakes. Chromosoma 1972, 38, 185-236. [CrossRef] [PubMed]

92. Poltronieri, J.; Marquioni, V.; Bertollo, L.A.C.; Kejnovsky, E.; Molina, W.F.; Liehr, T.; Cioffi, M.B. Comparative chromosomal mapping of microsatellites in Leporinus species (Characiformes, Anostomidae): Unequal accumulation on the $\mathrm{W}$ chromosomes. Cytogenet. Genome Res. 2014, 142, 40-45. [CrossRef]

93. Yano, C.F.; Bertollo, L.A.C.; Ezaz, T.; Trifonov, V.; Sember, A.; Liehr, T.; Cioffi, M.B. Highly conserved Z and molecularly diverged $\mathrm{W}$ chromosomes in the fish genus Triportheus (Characiformes, Triportheidae). Heredity 2017, 118, 276-283. [CrossRef]

94. Kretschmer, R.; de Oliveira, T.D.; de Oliveira Furo, I.; Oliveira Silva, F.A.; Gunski, R.J.; del Valle Garnero, A.; de Bello Cioffi, M.; de Oliveira, E.H.C.; de Freitas, T.R.O. Repetitive DNAs and shrink genomes: A chromosomal analysis in nine Columbidae species (Aves, Columbiformes). Genet. Mol. Biol. 2018, 41, 98-106. [CrossRef] 
95. Mank, J.E.; Promislow, D.E.L.; Avise, J.C. Evolution of alternative sex-determining mechanisms in teleost fishes. Biol. J. Linn. Soc. 2006, 87, 83-93. [CrossRef]

96. Cioffi, M.; Sánchez, A.; Marchal, J.A.; Kosyakova, N.; Liehr, T.; Trifonov, V.; Bertollo, L.A.C. Whole chromosome painting reveals independent origin of sex chromosomes in closely related forms of a fish species. Genetica 2011, 139, 1065. [CrossRef] [PubMed]

97. Vicoso, B.; Charlesworth, B. Effective population size and the Faster-X Effect: An extended model. Evolution 2009, 63, 2413-2426. [CrossRef]

98. Mank, J.E.; Nam, K.; Ellegren, H. Faster-Z evolution is predominantly due to genetic drift. Mol. Biol. Evol. 2010, 27, 661-670. [CrossRef] [PubMed]

99. Laopichienpong, N.; Muangmai, N.; Chanhome, L.; Suntrarachun, S.; Twilprawat, P.; Peyachoknagul, S.; Srikulnath, K. Evolutionary dynamics of the gametologous CTNNB1 gene on the Z and W chromosomes of snakes. J. Hered. 2017, 108, 142-151. [PubMed]

100. De Smet, W.H.O. Chromosomes of 23 species of snakes. Acta Zool. Pathol. Antverp. 1978, 70, 85-118.

101. Baker, R.J.; Mengden, G.A.; Bull, J.J. Karyotypic studies of thirty-eight species of North American snakes. Copeia 1972, 1972, 257-265. [CrossRef]

102. Laopichienpong, N.; Tawichasri, P.; Chanhome, L.; Phatcharakullawarawat, R.; Singchat, W.; Kantachumpoo, A.; Suntrarachun, S.; Matsubara, K.; Peyachoknagul, S.; Srikulnath, K. A novel method of caenophidian snake sex identification using molecular markers based on two gametologous genes. Ecol. Evol. 2017, 7, 4661-4669. [CrossRef]

(C) 2019 by the authors. Licensee MDPI, Basel, Switzerland. This article is an open access article distributed under the terms and conditions of the Creative Commons Attribution (CC BY) license (http://creativecommons.org/licenses/by/4.0/). 